\title{
Optimization of biomass, pellet size and polygalacturonase production by Aspergillus sojae ATCC 20235 using response surface methodology
}

\author{
C. Tari* ${ }^{*}$ N. Gögus, F. Tokatli \\ Department of Food Engineering, Izmir Institute of Technology, Urla, Izmir 35430, Turkey \\ Received 4 July 2006; received in revised form 16 August 2006; accepted 18 August 2006
}

\begin{abstract}
A two-step optimization procedure using central composite design with four factors (concentrations of maltrin and corn steep liquor (CSL), agitation speed and inoculation ratio) was used in order to investigate the effect of these parameters on the polygalacturonase (PG) enzyme activity, mycelia growth (biomass) and morphology (pellet size) of Aspergillus sojae ATCC 20235. According to the results of response surface methodology (RSM), initial concentrations of maltrin and CSL and agitation speed were significant $(p<0.05)$ on both PG enzyme production and biomass formation. As a result of this optimization, maximum PG activity $(13.5 \mathrm{U} / \mathrm{ml})$ was achievable at high maltrin $(120 \mathrm{~g} / \mathrm{l})$, at low CSL (0 g/l), high agitation speed $(350 \mathrm{rpm})$ and high inoculation ratio $\left(2 \times 10^{7}\right.$ total spore). Similarly, maximum biomass ( $\left.26 \mathrm{~g} / \mathrm{l}\right)$ could be obtained under the same conditions with only the difference for higher level of CSL requirement. The diameter of pellets in all optimization experiments ranged between 0.05 and $0.76 \mathrm{~cm}$. The second optimization step improved the PG activity by $74 \%$ and the biomass by $40 \%$.
\end{abstract}

(C) 2006 Elsevier Inc. All rights reserved.

Keywords: Aspergillus sojae; Pectinase; Submerged fermentation; Fungal morphology; Response surface methodology

\section{Introduction}

Enzymes that hydrolyzes pectic substances, which contribute to the firmness and structure of plant cells, are known as pectiolytic enzymes or pectinases. Based on their mode of action, these include, polygalacturonase (PG), pectin esterase, pectin lyase and pectate lyase [1]. Pectinases are extensively used in the industrial clarification of wine and fruit juice, in tomato pulp and oil extraction, in chocolate and tea fermentation and in vegetable waste treatment. In the fruit juice extraction and clarification process, these are used together with amylases whereby a reduction of $50 \%$ in the filtration time is observed [2,3]. Furthermore, in combination with other enzymes like cellulases, arabinases and xylanases they have shown to increase the pressing efficiency enormously [4]. Recent applications have emerged in the treatment and degumming of natural fibers used in paper and textile industry $[5,6]$. For example pectinases in conjunction with amylases, lipases, cellulases and hemicellulases have been used to remove the sizing agents from cotton, in a safe and eco-friendly

\footnotetext{
* Corresponding author. Tel.: +90 232 7506316; fax: +90 2327506196.

E-mail address: canantari@iyte.edu.tr (C. Tari).
}

manner by replacing toxic soda [7]. Moreover, pectinases are used in animal feed production reducing the feed viscosity and increasing the absorption of nutrients [7]. In the industrial market they contribute to almost $25 \%$ of the global enzyme sales, where this contribution is estimated to increase further by the year 2009 [1,8]. Therefore in order to meet this high demand, it is highly important to produce pectinase enzyme in a cost effective and productive way.

It is well documented, that several organisms are able to produce pectin degrading enzymes including plants, filamentous fungi, bacteria and yeast [9-12]. For industrial purposes moulds such as Aspergillus niger, Coniotryrium diplodiela, Penicillum and Rhizopus species are preferred, because as much as $90 \%$ of the enzyme can be excreted into the culture medium [9,13-15]. Pectinase production by filamentous fungi varies according to the type of strain, cultivation conditions $(\mathrm{pH}$, temperature, aeration, agitation and incubation time) and the growth medium composition (particularly carbon and nitrogen sources) [16]. Therefore these have to be specified individually for each and every single strain of interest.

In this study, Aspergillus sojae ATCC 20235 (from here on A. sojae only), which has been mostly used in the production of a well-known Japanese food (koji), by means of solid-state 
fermentation [12] is considered in the production of polygalacturonase enzyme (PG), which attracts the most attention among the family of pectionolytic enzymes due to its wide use. To best of our knowledge there is no literature report on the pectinase production by this organism in submerged or solid state fermentation. Therefore, this paper will be one of the initial studies working in this field.

In our previous study [17], it was demonstrated that this organism held a considerable potential for the production of the polygalacturonase enzyme. In the corresponding study it was shown that, if this organism was subcultured in molasses agar seed media and grown in complex growth media agitated at $250 \mathrm{rpm}$ at $30^{\circ} \mathrm{C}$, it would exhibit a pellet morphology that is of great interest to large scale submerged fermentations due to easier downstream processing. It was believed that with further optimization study using statistical tools such as response surface methodology (RSM), further increase in the enzyme yields could be attained. This determines the overall scope of this paper. As it is known, the application of statistical experimental design techniques in fermentation process development can result in improved product yields and reduced process variability, development time and overall costs [18]. With this perspective the concentrations of maltrin and corn steep liquor as carbon and nitrogen sources, respectively, together with inoculation ratio and agitation speed were chosen as the independent factor variables significant to large scale fermentations, using central composite design (CCD). The responses of interest were the PG enzyme activity, biomass and the pellet size as a measurement of the morphology of the culture.

The significance of this paper lays in the determination of the optimum regions for maximum PG production and biomass formation with a desired pellet morphology using low cost carbon and nitrogen sources. Therefore this paper will provide information, that can benefit the food and enzyme industry, and also be a new reference point for the microbiology area by providing knowledge regarding the growth requirement of $A$. sojae, which has been lacking so far in the literature.

\section{Materials and methods}

\subsection{Microorganism and spore production}

A. sojae ATCC 20235 was purchased in the lyophilized form, from Procochem Inc., an international distributor of ATCC (American Type of Culture Collection) in Europe. The propagation of this culture was done on YME agar slant medium containing, malt extract $(10 \mathrm{~g} / \mathrm{l})$, yeast extract $(4 \mathrm{~g} / \mathrm{l})$, glucose $(4 \mathrm{~g} / \mathrm{l})$ and agar $(20 \mathrm{~g} / \mathrm{l})$, incubated at $30^{\circ} \mathrm{C}$ until well sporulation (1 week). Stock cultures of these strains were prepared with $20 \%$ glycerol water and stored at $-80^{\circ} \mathrm{C}$.

The spore suspensions used as inoculum were obtained on molasses agar slants containing glycerol $(45 \mathrm{~g} / \mathrm{l})$, peptone $(18 \mathrm{~g} / \mathrm{l})$, molasses $(45 \mathrm{~g} / \mathrm{l})$, $\mathrm{NaCl}(5 \mathrm{~g} / \mathrm{l}), \mathrm{FeSO}_{4} \cdot 7 \mathrm{H}_{2} \mathrm{O}(15 \mathrm{mg} / \mathrm{l}), \mathrm{KH}_{2} \mathrm{PO}_{4}(60 \mathrm{mg} / \mathrm{l}), \mathrm{MgSO}_{4}(50 \mathrm{mg} / \mathrm{l})$, $\mathrm{CuSO}_{4} \cdot 5 \mathrm{H}_{2} \mathrm{O}(12 \mathrm{mg} / \mathrm{l}), \mathrm{MnSO}_{4} \cdot \mathrm{H}_{2} \mathrm{O}(15 \mathrm{mg} / \mathrm{l})$ and agar $(20 \mathrm{~g} / \mathrm{l})$, after the preactivation step performed on YME agar using the stock cultures. The incubation temperature and time for each of the steps were $30^{\circ} \mathrm{C}$ and 1 week, respectively. The harvesting of the spores from the slants was done using $5 \mathrm{ml}$ of Tween 80 -water $(0.02 \%)$. The spore suspension was collected in sterile falcon tube and stored at $4{ }^{\circ} \mathrm{C}$ until the actual study. The initial spore counts and viability counts were recorded.

\subsection{Production medium}

Total of 31 shake flasks media $(50 \mathrm{ml}$ in $250 \mathrm{ml}$ Erlenmeyer), including the repetitions performed at center points, were prepared according to the CCD (Tables 1 and 2) for each optimization step and experiments were conducted at $30^{\circ} \mathrm{C}$ for $96 \mathrm{~h}$ with an initial $\mathrm{pH}$ of 5.6. The basal medium consisted of glucose $(25 \mathrm{~g} / \mathrm{l})$, peptone $(2.5 \mathrm{~g} / \mathrm{l})$, disodium phosphate $(3.2 \mathrm{~g} / \mathrm{l})$ and monosodium phosphate $(3.3 \mathrm{~g} / \mathrm{l})$. In addition to this medium, maltrin and corn steep liquor were added according to the initial concentrations given in the design. After $96 \mathrm{~h}$ of incubation, each flask was assayed for enzyme activity, fungal morphology and biomass. Enzyme activity was determined on supernatant obtained after the centrifugation of the broth at $5000 \mathrm{rpm}$ for $15 \mathrm{~min}$.

\subsection{Enzyme assay}

PG (polygalacturunase) activity was assayed according to the procedure given by Panda et al. [19] by using $2.4 \mathrm{~g} / \mathrm{l}$ of polygalacturonic acid as substrate at $\mathrm{pH} 6.6$ and $26^{\circ} \mathrm{C}$. The amount of substrate and enzymes used were 0.4 and $0.086 \mathrm{ml}$, respectively. In this study, 1 unit of enzyme activity was defined as the amount of enzyme that catalyses the release of $1 \mu \mathrm{mol}$ of galacturonic acid per unit volume of culture filtrate per unit time at standard assay conditions. Galacturonic acid (Sigma, St. Louis, MO) was used as standard for the calibration curve of PG activity. PG activity was calculated by Eq. (1).

$\operatorname{Activity}(\mathrm{U} / \mathrm{ml})=\left(\frac{\mathrm{mg} \text { of galacturonic acid }}{212.12}\right)\left(\frac{1}{20}\right)\left(\frac{1}{0.086}\right)$

\subsection{Biomass determination and morphological measurements}

The final biomass expressed as dry cell weight $(\mathrm{g} / \mathrm{l})$ was determined by means of gravimetric method. The fermentation broth was filtered through the pre-weight Whatman No. 1 filter paper, followed by drying to constant weight at $40^{\circ} \mathrm{C}$ for approximately $24 \mathrm{~h}$.

Pellet morphology was characterized by using image analysis [20]. Pellet particles were analyzed for determination of the number of pellet per given volume and pellet size. The image was captured with a eurocam (Euromax, Holland) mounted on a phase contrast microscope (Novex, Holland). Image analysis was performed with the software package Image-Pro Plus 4.5.1 (Media Cybernetics Inc., Silver Spring, MD, USA). The size of the pellet was quantified using the diameter corresponding to a circular area equivalent to the pellet projected area [21].

\subsection{Experimental design and statistical analysis}

In this study, the effects of independent variables, initial concentrations of maltrin $\left(X_{1}\right)$ and corn steep liquor $\left(X_{2}\right)$, inoculation ratio in the form of total spores $\left(X_{3}\right)$ in $50 \mathrm{ml}$ of fermentation broth and agitation speed $\left(X_{4}\right)$ were investigated on the responses of PG activity, final biomass and morphology (pellet size) using RSM. A face centered CCD design with four factors were generated and conducted.

Analysis of data and generation of response surface graphics was done by Minitab statistical software (Release 13). After running the experiments and measuring the PG activity levels, biomass and pellet sizes, a second order model including interactions was fitted to the response data:

$Y=\beta_{0}+\sum_{i=1}^{k} \beta_{i} X_{i}+\sum_{i=1}^{k} \beta_{i i} X_{i}^{2}+\sum_{i} \sum_{j} \beta_{j} X_{i} X_{j}+\varepsilon$

where $Y$ is the predicted response, $k$ the number of factor variables, $\beta_{0}$ the model constant, $\beta_{i}$ the linear coefficient, $X_{i}$ the factor variable in its coded form, $\beta_{i i}$ the quadratic coefficient, and $\beta_{i j}$ is the interaction coefficient. Eq. (3) is used for coding the actual experimental values of the factors in a range of $[-1+1]$.

$x=\left[\frac{\text { actual }-(\text { low level }+ \text { high level }) / 2}{(\text { high level }- \text { low level }) / 2}\right]$

The analysis of variance (ANOVA) tables were generated and the effect and regression coefficients of individual linear, quadratic and interaction terms were 
Table 1

Results of face centered central composite design for the first optimization step in shake flask experiments conducted at $30^{\circ} \mathrm{C}$ for $96 \mathrm{~h}$ of incubation

\begin{tabular}{|c|c|c|c|c|c|c|}
\hline Run order & Maltrin $(g / l)$ & $\operatorname{CSL}(g / 1)$ & Agitation speed (rpm) & Inoculation ratio (total spore) & Activity $(\mathrm{U} / \mathrm{ml})$ & Biomass $(\mathrm{g} / \mathrm{l})$ \\
\hline $1^{\mathrm{a}}$ & 50 & 8.75 & 225 & $5.0 \times 10^{5}$ & 2.21 & 17.48 \\
\hline 2 & 25 & 2.5 & 150 & $7.5 \times 10^{5}$ & 0.76 & 10.67 \\
\hline 3 & 25 & 15.0 & 150 & $2.5 \times 10^{5}$ & 1.57 & 15.39 \\
\hline 5 & 75 & 15.0 & 300 & $7.5 \times 10^{5}$ & 4.81 & 22.12 \\
\hline 6 & 50 & 8.75 & 300 & $5.0 \times 10^{5}$ & 2.98 & 12.18 \\
\hline $7^{\mathrm{a}}$ & 50 & 8.75 & 225 & $5.0 \times 10^{5}$ & 3.55 & 18.59 \\
\hline 10 & 75 & 2.5 & 150 & $7.5 \times 10^{5}$ & 5.49 & 14.98 \\
\hline 11 & 25 & 2.5 & 300 & $2.5 \times 10^{5}$ & 1.72 & 7.81 \\
\hline $12^{\mathrm{a}}$ & 50 & 8.75 & 225 & $5.0 \times 10^{5}$ & 2.49 & 13.89 \\
\hline 13 & 25 & 2.5 & 300 & $7.5 \times 10^{5}$ & 2.72 & 9.93 \\
\hline 14 & 75 & 2.5 & 300 & $7.5 \times 10^{5}$ & 7.35 & 13.05 \\
\hline $15^{\mathrm{a}}$ & 50 & 8.5 & 225 & $5.0 \times 10^{5}$ & 3.13 & 18.88 \\
\hline 20 & 50 & 8.75 & 225 & $7.5 \times 10^{5}$ & 2.43 & 12.81 \\
\hline 21 & 25 & 8.75 & 225 & $5.0 \times 10^{5}$ & 0.91 & 17.15 \\
\hline 22 & 75 & 2.5 & 300 & $2.5 \times 10^{5}$ & 8.62 & 10.23 \\
\hline 23 & 50 & 2.5 & 225 & $5.0 \times 10^{5}$ & 4.35 & 10.34 \\
\hline 24 & 25 & 2.5 & 150 & $2.5 \times 10^{5}$ & 1.58 & 10.19 \\
\hline 25 & 75 & 2.5 & 150 & $2.5 \times 10^{5}$ & 4.57 & 13.14 \\
\hline 26 & 25 & 15 & 300 & $7.5 \times 10^{5}$ & 0.29 & 12.18 \\
\hline 27 & 50 & 8.75 & 225 & $2.5 \times 10^{5}$ & 3.63 & 16.60 \\
\hline $28^{\mathrm{a}}$ & 50 & 8.75 & 225 & $5.0 \times 10^{5}$ & 1.89 & 16.63 \\
\hline 29 & 50 & 15.0 & 225 & $5.0 \times 10^{5}$ & 2.15 & 20.69 \\
\hline 30 & 75 & 8.75 & 225 & $5.0 \times 10^{5}$ & 5.58 & 20.07 \\
\hline $31^{\mathrm{a}}$ & 50 & 8.75 & 225 & $5.0 \times 10^{5}$ & 2.52 & 14.61 \\
\hline
\end{tabular}

${ }^{a}$ The average and the standard deviation among the repeated experiments performed at center points were $2.497 \pm 0.6598 \mathrm{U} / \mathrm{ml}$ and $16.288 \pm 2.14 \mathrm{~g} / \mathrm{ml}$ for PG activity and biomass, respectively.

determined. The significances of all terms in the polynomial were judged statistically according to the $p$-value. $p$-Values were compared to the significance level of 5\%. In the second optimization step 3 out of 31 experiments resulted in clump type of morphology. The mean diameter of these were taken as $3.0 \mathrm{~cm}$ for the evaluation of the results.

\section{Results and discussion}

Factors like carbon and nitrogen sources and their concentrations have always been of great interest to the researchers in the industry for the low cost media design especially when strains lacking information on their growth requirements, are under consideration such as the case here [22,23]. It is also known that $30-40 \%$ of the production cost of industrial enzymes is estimated to be the cost of growth medium [24]. These sources together with factors like agitation speed and inoculation ratio, besides their effect on the product formation, have been determined to play significant role in the determination of the final morphology of the culture [25]. Therefore, it is of great significance to optimize the conditions for cost-efficient enzyme production. With this perspective, a study was initiated with the goal of designing a low cost media using maltrin and cornsteep liquor as carbon and nitrogen sources, which would promote maximum PG production of a strain which has not been considered for this purpose so far, and specifying the necessary agitation speed and inoculation ratio that would also result into pellet morphology preferred in large scale fermentations. As discussed above, another parameter that needs attention with respect to its effect on the fermentation run and downstream processing is the fungal morphology (pellet size). It is well known that a uniform small pellet size is preferred in many fungal fermentations due to its easier downstream processing and a better oxygen and nutrient mass transfer during the course of the fermentation [26]. Besides the PG enzyme production, the fungal biomass was also considered due to its significance in applications of waste treatment and feed stocks. For such applications its maximization during the fermentation processes might be vital where it becomes the product of interest [27-31]. For example in waste treatments, it is cheaper and more feasible to use the microorganism itself (biomass) as the source of the enzymes which are required to degrade the waste. Especially fungal organisms are very suitable for such treatments due to their capability of producing various enzymes. Based on this assumption, in order to utilize the biomass which is mostly taken as waste, the goal was also to provide the conditions for maximum biomass formation. All these three output variables were taken into consideration in the optimization procedure and their interactive relation was tried to be investigated. 
Table 2

Results of face centered central composite design for the second optimization step in shake flask experiments conducted at $30{ }^{\circ} \mathrm{C}$ for $96 \mathrm{~h}$ of incubation

\begin{tabular}{|c|c|c|c|c|c|c|c|}
\hline Run order & Maltrin (g/l) & $\operatorname{CSL}(g / 1)$ & Agitation (rpm) & Inoculation ratio (total spore) & Activity (U/ml) & Average pellet size $(\mathrm{cm})$ & Biomass $(\mathrm{g} / \mathrm{l})$ \\
\hline 1 & 50 & 0 & 350 & $2.0 \times 10^{7}$ & 9.63 & 0.30 & 7.59 \\
\hline 2 & 120 & 5.0 & 350 & $2.0 \times 10^{7}$ & 8.73 & 3.00 & 31.49 \\
\hline $3^{\mathrm{a}}$ & 85 & 2.5 & 250 & $1.0 \times 10^{7}$ & 6.95 & 0.09 & 22.54 \\
\hline 4 & 85 & 0 & 250 & $1.0 \times 10^{7}$ & 10.46 & 0.15 & 10.09 \\
\hline $5^{\mathrm{a}}$ & 85 & 2.5 & 250 & $1.0 \times 10^{7}$ & 6.13 & 0.14 & 18.28 \\
\hline 6 & 120 & 0 & 150 & $2.0 \times 10^{7}$ & 11.29 & 0.06 & 11.03 \\
\hline 7 & 120 & 0 & 350 & $1.25 \times 10^{4}$ & 10.55 & 0.11 & 6.82 \\
\hline 8 & 120 & 2.5 & 250 & $1.0 \times 10^{7}$ & 7.87 & 0.16 & 23.02 \\
\hline 9 & 50 & 5.0 & 150 & $1.25 \times 10^{4}$ & 1.89 & 0.53 & 13.28 \\
\hline 10 & 50 & 5.0 & 350 & $2.0 \times 10^{7}$ & 2.37 & 3.00 & 20.49 \\
\hline 11 & 85 & 2.5 & 250 & $2.0 \times 10^{7}$ & 5.33 & 0.13 & 18.49 \\
\hline 12 & 50 & 5.0 & 150 & $2.0 \times 10^{7}$ & 1.03 & 0.09 & 20.62 \\
\hline 13 & 120 & 0 & 150 & $1.25 \times 10^{4}$ & 13.50 & 0.16 & 7.56 \\
\hline 14 & 85 & 2.5 & 150 & $1.0 \times 10^{7}$ & 5.28 & 0.28 & 10.00 \\
\hline $15^{\mathrm{a}}$ & 85 & 2.5 & 250 & $1.0 \times 10^{7}$ & 6.36 & 0.76 & 13.13 \\
\hline 16 & 50 & 2.5 & 250 & $1.0 \times 10^{7}$ & 4.17 & 0.10 & 14.99 \\
\hline 17 & 120 & 5.0 & 150 & $1.25 \times 10^{4}$ & 10.47 & 3.00 & 26.63 \\
\hline $18^{\mathrm{a}}$ & 85 & 2.5 & 250 & $1.0 \times 10^{7}$ & 6.16 & 0.16 & 20.76 \\
\hline 19 & 120 & 5.0 & 350 & $1.25 \times 10^{4}$ & 11.02 & 0.40 & 18.46 \\
\hline 20 & 50 & 0 & 350 & $1.25 \times 10^{4}$ & 8.96 & 0.16 & 4.07 \\
\hline 21 & 120 & 0 & 350 & $2.0 \times 10^{7}$ & 15.43 & 0.32 & 12.04 \\
\hline $22^{\mathrm{a}}$ & 85 & 2.5 & 250 & $1.0 \times 10^{7}$ & 7.578 & 0.11 & 17.01 \\
\hline 23 & 50 & 0 & 150 & $2.0 \times 10^{7}$ & 9.32 & 0.05 & 7.84 \\
\hline 24 & 85 & 5.0 & 250 & $1.0 \times 10^{7}$ & 5.17 & 0.09 & 18.54 \\
\hline 25 & 85 & 2.5 & 250 & $1.25 \times 10^{4}$ & 7.37 & 0.30 & 13.50 \\
\hline $26^{\mathrm{a}}$ & 85 & 2.5 & 250 & $1.0 \times 10^{7}$ & 6.10 & 0.11 & 18.75 \\
\hline 27 & 120 & 5.0 & 150 & $2.0 \times 10^{7}$ & 8.13 & 0.16 & 10.09 \\
\hline 28 & 50 & 0 & 150 & $1.25 \times 10^{4}$ & 8.81 & 0.17 & 1.87 \\
\hline 29 & 85 & 2.5 & 350 & $1.0 \times 10^{7}$ & 6.86 & 0.06 & 22.56 \\
\hline 30 & 50 & 5.0 & 350 & $1.25 \times 10^{4}$ & 1.31 & 0.63 & 12.53 \\
\hline $31^{\mathrm{a}}$ & 85 & 2.5 & 250 & $1.0 \times 10^{7}$ & 5.69 & 0.16 & 19.14 \\
\hline
\end{tabular}

${ }^{a}$ The average and the standard deviation among the repeated experiments performed at center points were $6.54 \pm 0.59 \mathrm{U} / \mathrm{ml}, 18.41 \pm 3.24 \mathrm{~g} / \mathrm{ml}$ and $0.23 \pm 0.26 \mathrm{~cm}$ for PG activity, biomass and pellet size, respectively.

Since it was not possible in a single step to obtain real optimum regions for maximum PG and biomass, a two-step optimization procedure was applied using CCD. In the first step the four independent variables, concentrations of maltrin $\left(X_{1}\right)$ and corn steep liquor $\left(X_{2}\right)$, agitation speed $\left(X_{3}\right)$ and inoculation ratio $\left(X_{4}\right)$ were used. In the second step a CCD design with the same factors with new ranges based on the first step were applied. The first step served as a preliminary study for the determination of the initial levels, since there is no literature information available on this strain that could be used initially.

\subsection{First optimization step}

A face-centered central composite design with 31 experiments was performed. The respective low and high levels with the coded levels in parentheses for the factors were defined as $25(-1)$ and $75(+1) \mathrm{g} / \mathrm{l}$ for maltrin, $2.5(-1)$ and $15(+1) \mathrm{g} / \mathrm{l}$ for CSL, $150(-1)$ and $300(+1) \mathrm{rpm}$ for agitation speed, and $2.5 \times 10^{5}(-1)$ and $7.5 \times 10^{5}(+1)$ total spore for inoculation ratio. The experimental runs with their response variables (PG activity, biomass) are presented in Table 1 . The coefficients of the models in coded units and their significance levels are presented in Table 3. The adjusted $R^{2}$ of the models were $83.2 \%$ and $71.3 \%$ with an insignificant lack of fit of 0.287 and 0.696 for PG and
Table 3

Analysis of variance for the first optimization step in shake flask experiments conducted at $30^{\circ} \mathrm{C}$ for $96 \mathrm{~h}$ of incubation ${ }^{\mathrm{a}}$

\begin{tabular}{lll}
\hline Term & Parameter estimates & $p$-Value \\
\hline Estimated regression coefficients for PG activity & \\
Constant & 3.0580 & 0.000 \\
Maltrin & 2.0322 & 0.000 \\
CSL & -0.7906 & 0.000 \\
Agitation speed & 0.5136 & 0.011 \\
Inoculum ratio & -0.1619 & 0.395 \\
Maltrin $\times$ CSL & -0.4130 & 0.048 \\
Agitation speed $\times$ CSL & -0.5048 & 0.018 \\
$S=0.7937, R^{2}=86.6 \%, R^{2}($ adj $)=83.2 \%$ & \\
& & \\
Estimated regression coefficients for biomass & \\
Constant & 15.995 & 0.000 \\
Maltrin & 1.6633 & 0.001 \\
CSL & 3.1207 & 0.000 \\
Agitation speed & -0.9693 & 0.045 \\
Inoculation ratio & 0.8051 & 0.092 \\
Maltrin $\times$ maltrin & 1.8781 & 0.085 \\
Agitation speed $\times$ agitation speed & -3.6679 & 0.002 \\
$S=1.948, R^{2}=77.0 \%, R^{2}($ adj $)=71.3$ & &
\end{tabular}

\footnotetext{
a Analysis by using coded units.
} 
biomass, respectively, indicating a good fit between the models and the experimental data. The maximum PG activity $(8.6 \mathrm{U} / \mathrm{ml})$ could be achieved at higher maltrin and lower CSL concentrations and at higher agitation speeds. For maximum biomass formation, high maltrin and high CSL concentrations with an optimum agitation speed ranging between 200 and $250 \mathrm{rpm}$ were required. The inoculation ratio was insignificant under ranges studied. However these values did not result into true optima yet. Therefore another optimization study was suggested by decreasing the CSL level and increasing the maltrin level and agitation speed further for maximization of the enzyme activity. The incubator shaker used was not suitable for further increase in agitation speed that is why the maximum speed was leveled at $350 \mathrm{rpm}$. Since the inoculation ratio under the ranges studied did not affect the PG activity and biomass significantly, a wider range for this factor was studied in the second step.

\subsection{Second optimization step}

New factor values with higher maltrin $\left(X_{1}\right)$ and lower CSL $\left(X_{2}\right)$ concentrations and higher agitation speed $\left(X_{3}\right)$ and wider inoculation ratio $\left(X_{4}\right)$ range were proposed. An additional 31 experiment using 4-factor central composite design was performed. The experimental runs with their response variables (PG activity, biomass and morphology (pellet size)) are presented in Table 2. The respective low and high levels with the coded levels in parentheses for the factors were defined as $50(-1)$ and $120(+1) \mathrm{g} / \mathrm{l}$ for maltrin, $0(-1)$ and $5(+1) \mathrm{g} / \mathrm{l}$ for CSL and 150 $(-1)$ and $350(+1) \mathrm{rpm}$ for agitation speed and $1.25 \times 10^{4}(-1)$ and $2 \times 10^{7}(+1)$ total spore for inoculation ratio. The analysis of variance for the second optimization step is presented in Table 4. After the treatment combinations all linear terms of the independent variables, quadratic term of CSL $\left(X_{2}\right)$, interaction terms of CSL with maltrin $\left(X_{1} X_{2}\right)$ and inoculum $\left(X_{2} X_{4}\right)$ and interaction terms of agitation and inoculation ratio $\left(X_{3} X_{4}\right)$ were included in the model for PG activity since these were significant $(p<0.05)$. Even though variables $X_{3}$ and $X_{4}$ were not found statistically significant $(p>0.05)$, they were added to the model due to their significant interaction effects. Considering biomass as the response, all linear terms and quadratic term of CSL $\left(X_{2} X_{2}\right)$ together with the interaction terms of maltrin with inoculum $\left(X_{1} X_{4}\right)$ and interaction terms of agitation speed with inoculum $\left(X_{3} X_{4}\right)$ were significant and therefore included in the model. Similarly, taking pellet size as a morphological measurement, the linear terms of maltrin, CSL, agitation speed and inoculation ratio together with quadratic term of inoculation ratio $\left(X_{4} X_{4}\right)$ and interaction terms of agitation speed with maltrin $\left(X_{1} X_{3}\right)$ and inoculation ratio $\left(X_{3} X_{4}\right)$ were included in the model equation. Data for the mean diameter of pellets were transformed to get the normally distributed data in the RSM by taking the inverse of the square root of pellet diameter. In all 31 experiments, diameter values varied between 0.05 and $0.63 \mathrm{~cm}$ except three experiments that ended with the clumps of $3 \mathrm{~cm}$ diameter. For all of the models the adjusted $R^{2}$ values were $92.5 \%, 66.6 \%$ and $66.5 \%$ with insignificant lack of fit values of $0.126,196$ and $0.085(p>0.05)$ for PG activity, biomass and pellet size, respectively. The model equations for $\mathrm{PG}$ enzyme $\left(Y_{\mathrm{PG}}\right)$, biomass $\left(Y_{\mathrm{b}}\right)$
Table 4

Table of analysis of variance for the second optimization step in shake flask experiments conducted at $30^{\circ} \mathrm{C}$ for $96 \mathrm{~h}$ of incubation ${ }^{\mathrm{a}}$

\begin{tabular}{|c|c|c|}
\hline Term & Parameter estimates & $p$-Value \\
\hline \multicolumn{3}{|c|}{ Estimated regression coefficients for PG activity } \\
\hline Constant & 6.2969 & 0.000 \\
\hline Agitation & 0.2859 & 0.202 \\
\hline Inoculum & -0.1467 & 0.507 \\
\hline Maltrin & 2.7500 & 0.000 \\
\hline CSL & -2.6570 & 0.000 \\
\hline $\mathrm{CSL} \times \mathrm{CSL}$ & 1.9303 & 0.000 \\
\hline Agitation $\times$ inoculum & 0.5768 & 0.020 \\
\hline Inoculum $\times$ CSL & -0.5184 & 0.035 \\
\hline Maltrin $\times$ CSL & 1.1069 & 0.000 \\
\hline \multicolumn{3}{|c|}{$S=0.9226, R^{2}=94.5 \%, R^{2}(\operatorname{adj})=92.5 \%$} \\
\hline \multicolumn{3}{|c|}{ Estimated regression coefficients for biomass } \\
\hline Constant & 17.861 & 0.000 \\
\hline Agitation & 1.508 & 0.118 \\
\hline Inoculum & 1.942 & 0.048 \\
\hline Maltrin & 2.436 & 0.015 \\
\hline CSL & 5.735 & 0.000 \\
\hline $\mathrm{CSL} \times \mathrm{CSL}$ & -4.469 & 0.005 \\
\hline Agitation $\times$ inoculum & 1.845 & 0.074 \\
\hline Inoculum $\times$ maltrin & -1.227 & 0.225 \\
\hline \multicolumn{3}{|c|}{$S=3.940, R^{2}=74.4 \%, R^{2}(\mathrm{adj})=66.6 \%$} \\
\hline \multicolumn{3}{|c|}{ Estimated regression coefficients for inv (sqrt) } \\
\hline Constant & 2.96587 & 0.000 \\
\hline Agitation & -0.35666 & 0.017 \\
\hline Inoculum & 0.28031 & 0.054 \\
\hline Maltrin & -0.08949 & 0.524 \\
\hline CSL & -0.57699 & 0.000 \\
\hline Inoculum $\times$ inoculum & -0.78790 & 0.001 \\
\hline Agitation $\times$ inoculum & -0.70409 & 0.000 \\
\hline Agitation $\times$ maltrin & 0.16174 & 0.282 \\
\hline
\end{tabular}

a Analysis by using coded units.

and $1 / \sqrt{\text { pelle } t \text { size }}\left(Y_{\mathrm{p}}\right)$ with the coefficients in coded units of factors are given below:

$$
\begin{aligned}
Y_{\mathrm{PG}}= & 6.29+2.75 X_{1}-2.657 X_{2}+0.286 X_{3}-0.147 X_{4} \\
& +1.93 X_{2}^{2}+1.107 X_{1} X_{2}-0.518 X_{2} X_{4}+0.577 X_{3} X_{4} \\
Y_{\mathrm{b}}= & 17.86+2.436 X_{1}+5.735 X_{2}+1.508 X_{3}+1.942 X_{4} \\
& -4.469 X_{2}^{2}-1.227 X_{1} X_{4}+1.845 X_{3} X_{4} \\
Y_{\mathrm{p}}= & 2.97-0.089 X_{1}-0.577 X_{2}-0.356 X_{3}+0.280 X_{4} \\
& -0.788 X_{4}^{2}+0.161 X_{1} X_{3}-0.704 X_{3} X_{4}
\end{aligned}
$$

From the response surface graphs (Fig. 1a) presenting the interaction of maltrin and CSL it is obvious that maximum PG activities can be obtained at high maltrin $(120 \mathrm{~g} / \mathrm{l})$ and in the absence of CSL $(0 \mathrm{~g} / \mathrm{l})$ concentrations. This confirms the result of the first optimization study. However, when the interaction of agitation speed and inoculation ratio is considered, the situation changes where two options become available (Fig. 1b). In 


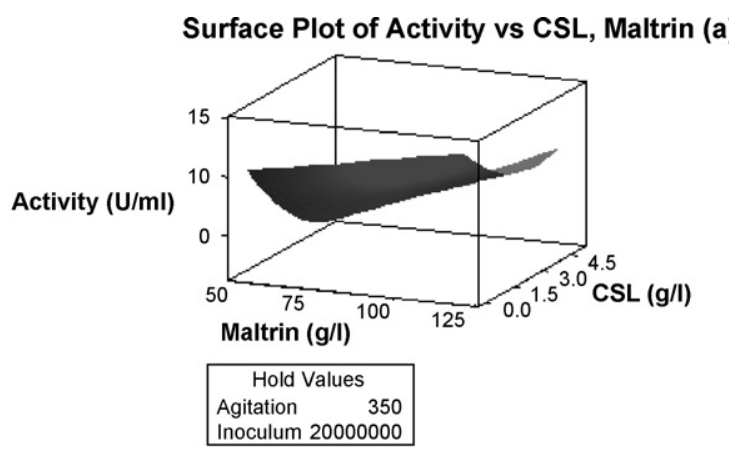

Surface Plot of Activity vs Inoculum, Agitation (b)

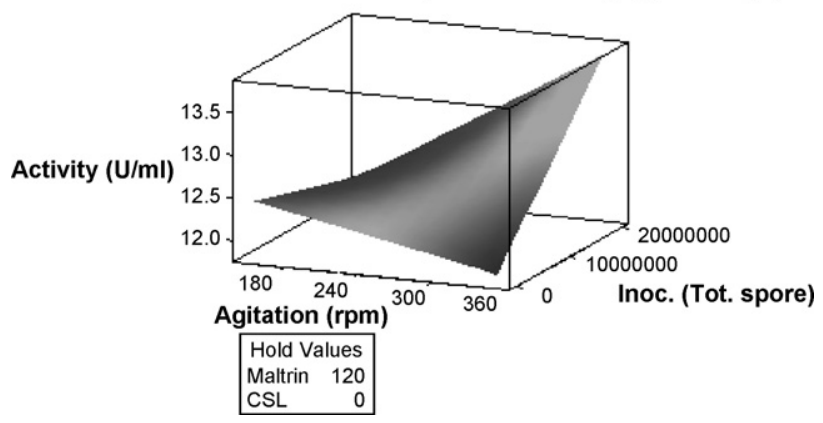

Fig. 1. Response surface plot of PG activity in 4-factor face centered central composite design showing the interaction of (a) the concentrations of maltrin with CSL and (b) agitation speed with inoculation ratio.

this case maximum enzyme production is achievable either at low agitation speed together with low inoculation ratio or high agitation speed together with high inoculation ratio. This is due to the fact that agitation speed influences the mass transfer of oxygen and nutrients. It is logical that high inoculum requires more oxygen and nutrient transfer which is supported through the higher agitation. Therefore, a lower inoculum of cells will require less oxygen and nutrient transfer. The same rule is valid for biomass formation which is depicted through the figures presented (Fig. 2a). In addition to these conditions maximum biomass formation required higher levels of CSL (Fig. 2b). This situation rises the following conclusion: if one wants to produce high enzyme, then the preference of CSL concentration has to be on the lower end, however if the primary goal is to produce biomass, the only difference would be to add more CSL. Comparing the two optimization steps, the second step improved the enzyme activity by $74 \%$, and biomass by $40 \%$.

From the response surface graphs (Fig. 3) showing the interaction of agitation speed with inoculation ratio on the response variable $1 / \sqrt{\text { pellet size }}$ at low CSL and low maltrin concentrations, it is observed that bigger pellets (see where low

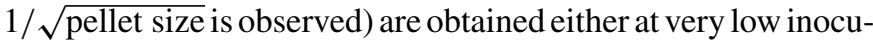
lation ratio and low agitation speed or very high inoculation ratio and high agitation speed. This is due to the fact that higher agitation speed increases the mass transfer of nutrient and oxygen to the cells and also promotes aggregation of the mycelial biomass in the form of pellets and clumps. This indicates indirectly the mechanism for pellet formation that can be related to aggregation of pellets at higher speeds [32]. Therefore lower speed is not sufficient to bring the pellets together and to provide enough
Surface Plot of Biomass vs Inoculum, Agitation (a)

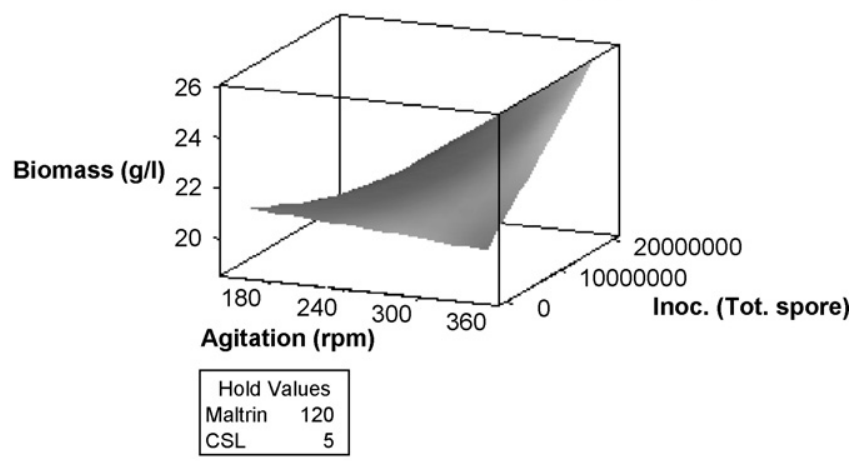

Surface Plot of Biomass vs CSL, Maltrin (b)

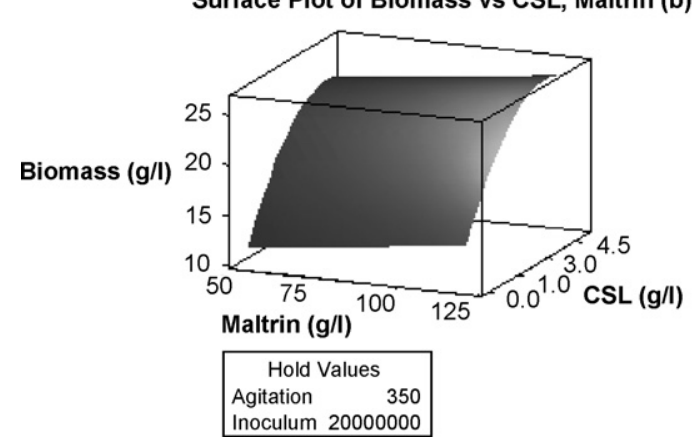

Fig. 2. Response surface plot of biomass in 4-factor face centered central composite design showing the interaction of (a) agitation speed with inoculation ratio and (b) the concentrations of maltrin with CSL.

nutrient and oxygen mass transfer at high inoculation levels. Smaller pellet sizes (see where high $1 / \sqrt{\text { pellet size is observed) }}$ are obtainable, at low agitation speed, with an optimum inoculation ratio of $1.7 \times 10^{7}$ total spore (in $50 \mathrm{ml}$ of fermentation medium). Smaller pellets which can also be observed at low inoculation levels and at higher speeds could be due to the toxic effect of oxygen, that might be in surplus.

Overall, in order to achieve a high PG activity, maltrin concentration should be $120 \mathrm{~g} / \mathrm{l}$, while CSL concentration should be as low as possible or none. Agitation speed and inoculum ratio should be $350 \mathrm{rpm}$ and $2 \times 10^{7}$, respectively. For biomass on the other hand, CSL concentration should be kept higher $(\sim 4 \mathrm{~g} / \mathrm{l})$ to

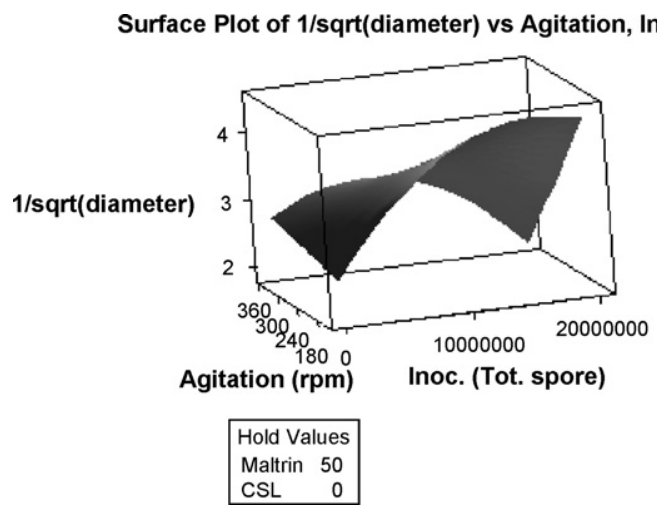

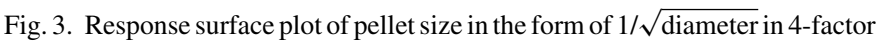
face centered central composite design showing the interaction of agitation speed with inoculation ratio. 
Table 5

Results of experimental and predicted values for PG activity and biomass at optimum conditions

\begin{tabular}{|c|c|c|c|c|c|c|}
\hline Experiment number & Maltrin $(\mathrm{g} / \mathrm{l})$ & $\operatorname{CSL}(g / 1)$ & Agitation (rpm) & Inoculum (total spore) & PG activity $^{\mathrm{a}}(\mathrm{U} / \mathrm{ml})$ & $\operatorname{Biomass}^{\mathrm{a}}(\mathrm{g} / \mathrm{l})$ \\
\hline 1 & 120 & 0 & 350 & $2.0 \times 10^{7}$ & $13.16(13.8)$ & $5.08(14.1)$ \\
\hline 2 & 150 & 0 & 350 & $2.0 \times 10^{7}$ & $13.82(14.2)$ & $6.27(15.1)$ \\
\hline 3 & 180 & 0 & 350 & $2.0 \times 10^{7}$ & $16.65(16.6)$ & $9.82(16.2)$ \\
\hline 4 & 120 & 4.10 & 350 & $2.0 \times 10^{7}$ & $5.82(9.2)$ & $40.37(26.1)$ \\
\hline
\end{tabular}

a Predicted values of responses are in the paranthesis.

have a high biomass concentration. Other conditions match to the ones for high enzyme activity. For high enzyme activity, the mean diameter of pellets was observed as $0.32 \mathrm{~cm}$ among particles ranged between 0.05 and $0.76 \mathrm{~cm}$ in diameter (Table 2).

\subsection{Validation of the models}

In order to validate the adequacy of the model equations a total of four verification experiments that were repeated twice were carried out at the predicted optimum conditions. The mean values of the experimental data and the predicted responses are given in Table 5. As it is seen from Table 5 and Fig. 4, there was a good correlation between the experimental and predicted values of the PG activity indicating a good fit of the model. However, the experimental biomass values were observed higher than the predicted ones. Also increasing the maltrin concentration to $180 \mathrm{~g} / \mathrm{l}$ increased the PG activity slightly. The pellets observed at the optimum conditions of the validation experiments revealed that large number of small size pellets (average of $0.08 \mathrm{~cm}$ in diameter) were obtained. The diameter of pellets ranged between 0.03 and $0.36 \mathrm{~cm}$ with an average of $0.08 \mathrm{~cm}$. This was still in
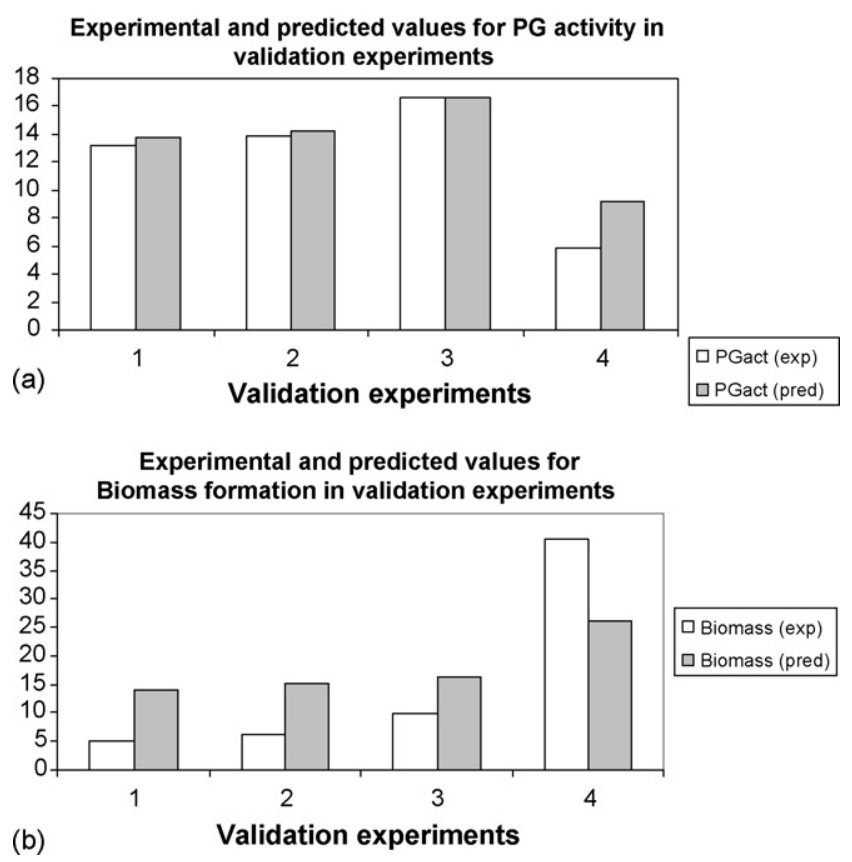

Fig. 4. Experimental and predicted values for (a) PG activity and (b) biomass formation in validation experiments. the range of $0.05-0.76 \mathrm{~cm}$ in diameter obtained in the optimization experiments. The clump morphology observed at maximum biomass formation was in agreement with clump formation in the validation experiment.

In the comparison of the current results with the literature studies conducted on pectinase production using different fungal organisms, reveals that the enzyme activity obtained in this study, is above the range of those results $[1,13,33]$. For example in a study conducted by Panda et al. [19] in the multi response analysis of microbiological parameters affecting the production of pectolytic enzymes by $A$. niger, the maximum PG activity obtained was around $0.91 \mathrm{U} / \mathrm{ml}$ which is lower than our results. Similarly in another study conducted by Blandino et al. [13] using Aspergillus awamori in the polygalacturonase production, the maximum activity in defined medium was around $0.05 \mathrm{U} / \mathrm{ml}$, which is below the results we obtained in this study. In the comparison of the biomass results with literature, our results are within the ranges of other researchers [13,33]. The pellet sizes which are taken as a means of morphological measurements in this study, are comparable to the results of various researcher who also relate these to the broth rheology during the fermentation [32,34]. With this perspective this study is indicative of providing informations on the conditions for biomass and certain pellet size formation that could be related to other rheological and model development studies for various fungal fermentations $[25,35]$. For example it is emphasized by a study conducted by Fatile [36], and Olsvik et al. [35], that the shape of mycelial aggregates (such as pellets) and the biomass concentration are correlated to the rheological properties of the broth. Broth rheology is important since it has profound effect on the mass transfer properties of nutrient and oxygen during the fermentation run and the downstream processing. In downstream processing problems due to the difficulties in establishing and maintaining fluid flow in pipe lines used to transport the broth to and from fermentation vessels and biomass filtration for product recovery may arise from very viscous fermentation broth which are the result of the rheology of the broth [32].

This study clearly indicates that this strain with the optimized conditions can be considered as a potential pectinase producer for different industrial applications. Furthermore, with potential high biomass formation it can also be considered for waste treatment purposes with the possibility of producing other enzymes and metabolites that needs further investigation. These optimized conditions also provide a desired pellet size through the pellet morphology that exhibits throughout the course of the fermentation, which not only benefit the fermentation run 
but also the subsequent downstream processes by reducing the operational cost. Besides data on the pellet sizes and biomass will be useful in providing informations for the development of mathematical models describing fungal fermentations and be indicative in scale up procedures.

\section{Conclusions}

To date, no reports are available in literature regarding the optimization of fermentation conditions for mycelial growth, pellet size and PG enzyme production by A. sojae. Therefore, this study will serve as a base line of the initial studies in this field. The study does not only provide novel information on the growth requirement of this organism, but also serves as an example for the application of the statistical techniques to the fungal systems by giving the end user flexibility for choosing the optimized conditions depending on the responses of interest such as enzyme production, biomass formation or the necessary pellet size for an easy downstream process. Through these optimization experiments, the optimal conditions for maximum PG enzyme activity were to use maltrin at $120 \mathrm{~g} / \mathrm{l}$, exclude CSL, with an agitation speed of $350 \mathrm{rpm}$ and an inoculation ratio of $2 \times 10^{7}$ total spore. Similarly if the primary goal is the maximization of biomass formation then the preferred conditions would be to include CSL in the concentration of $4 \mathrm{~g} / \mathrm{l}$ to the given parameters above. The pellet sizes under these conditions would range from 0.05 to $0.76 \mathrm{~cm}$ in diameter for maximum PG production and being mostly clump for maximum biomass formation.

\section{Acknowledgements}

Financial support of Izmir Institute of Technology through the projects IYTE 2004,04 and IYTE 2004,08 is gratefully acknowledged.

\section{References}

[1] Kaur G, Kumar S, Satyanarayana T. Production, characterization and application of a thermostable polygalacturonase of a thermophilic mould Sporotrichum thermophile Apinis. Bioresour Technol 2004;94: 239-43.

[2] Jayani RS, Saxena S, Gupta R. Microbial pectinolytic enzymes: a review. Process Biochem 2005;40(9):2931-44.

[3] Blanco P, Sieiro C, Villa TG. Production of pectic enzymes in yeasts. FEMS Microbiol Lett 1999;175:1-9.

[4] Gailing MF, Guibert A, Combes D. Fractional factorial designs applied to enzymatic sugar beet pulps pressing improvement. Bioprocess Eng 2000;22:69-74.

[5] Almeida C, Branyik T, Ferreira PM, Teixeira J. Use of two different carriers in a packed bed reactor for endopolygalacturonase production by a yeast strain. Process Biochem 2004;40(5):1937-42.

[6] Kashyap DR, Vohra PK, Chopra S, Tewari R. Applications of pectinases in the commercial sector: a review. Bioresour Technol 2001;77:215-27.

[7] Hoondal GS, Tiwari RP, Tiwari T, Dahiya N, Beg QK. Microbial alkaline pectinases and their applications: a review. Appl Microbiol Biotechnol 2002;59:409-18.

[8] Business Cooperate Inc. www.bccresearch.com/chem/C147U.html. Enzymes for industrial applications, 2006.
[9] Silva EG, Borges MF, Medina C, Piccoli RH, Schwan RF. Pectinolytic enzymes secreted by yeast from tropical fruits. FEMS Yeast Res 2005;5:859-65.

[10] De Vries RP, Viesser J. Aspergillus enzymes involved in degradation of plant cell wall polysaccharides. Microbiol Mol Biol Rev 2001;65:497-522.

[11] Prade RA, Zhan DF, Ayoubi P, Mort AJ. Pectins, pectinases and plant-microbe interactions. Biotechnol Genetic Eng Rev 1999;16: 361-91.

[12] Behere A, Satyanarayan V, Desai RP. Separation and limited characterization of three polygalacturonases of Aspergillus niger. Enzyme Microb Technol 1993;15:158-61.

[13] Blandino A, Dravillas K, Cantero D, Pandiella SS, Webb C. Utilisation of whole wheat flour for the production of extracellular pectinases by some fungal strains. Process Biochem 2001;37:497-503.

[14] Schwan RF, Wheals AE. The microbiology of cocoa fermentation and its role in chocolate quality. Crit Rev Food Sci Nutr 2004;44:205-22.

[15] Souza JVB, Silva ES, Maia MLS, Teixeira MFS. Screening of fungal strains for pectinolytic activity: endopolygalacturonase production by Peacilomyces clavisporus 2A. UMIDA.1. Process Biochem 2003;39:455-8.

[16] Benett JW. Aspergillus and koji: history, practice and molecular biology. Soc Ind Enzymes News 2001;51:65-71.

[17] Gogus N, Tari C, Oncü S, Unluturk S, Tokatli F. Investigation of the relationship morphology rheology and polygalacturonase production by Aspergillus sojae 20235 in submerged cultures. Biochem Eng J [submitted for publication].

[18] Elibol M. Optimization of medium composition for actinorhodin production by Streptomyces coelicolor A3(2) with response surface methodology. Process Biochem 2003;39:1057-62.

[19] Panda T, Naidu GSN, Sinha J. Multiresponse analysis of microbiological parameters affecting the production of pectolytic enzymes by Aspergillus niger: a statistical view. Process Biochem 1999;35:187-95.

[20] Cox PW, Thomas CR. Classification and measurement of fungal pellets by automated image analysis. Biotechnol Bioeng 1992;39:945-52.

[21] Lopez LC, Perez JAS, Sevilla JMF, Porcel EMJ, Chisti Y. Pellet morphology, culture rheology and lovastatin production in cultures of Aspergillus terreus. J Biotechnol 2005;116:61-77.

[22] Parra R, Aldred D, Magan N. Medium optimization for the production of secondary metabolite squalestatin S1 bty a Phoma sp. Combining orthogonal design and response surface methodology. Enzyme Microb Technol 2005;37:704-11.

[23] Tari C, Genckal H, Tokatli F. Optimization of a growth medium using a statistical approach for the production of an alkaline protease by a newly isolated Bacillus sp. L21. Process Biochem 2006;41:659-65.

[24] Laxman RS, Sonawane AP, More SV, Rao BS, Rele MV, Jogdand VV, et al. Optimization and scale up of production of alkaline protease from Conidiobolus coronatus. Process Biochem 2005;40(9):3152-8.

[25] Papagianni M. Fungal morphology and metabolite production in submerged mycelial processes. Biotechnol Adv 2004;22:189-259.

[26] Pamboukian CRD, Facciotti MCR, Schmidell W. Relationship between morphology, rheology and glucoamylase production by Aspergillus awamori in submerged cultures. Braz J Chem Eng 1998;15(3):1-8.

[27] Field JA, Jong E, Feijo CG, DeBont JA. Biodegradation of polycylic aromatic hydrocarbons by new isolates of white rot fungi. Appl Environ Microbiol 1992;58(7):2219-26.

[28] Milstein O, Gersonde R, Hutterman A, Chen MJ, Meister JJ. Fungal biodegradation of lignopolystyren graft polymers. Appl Environ Microbiol 1992;52(10):3225-32.

[29] Zhang H, Qi HY. Pectinase production by Aspergillus niger using biomass waste in solid state fermentation. CN Patent 1271774A; 2000.

[30] Hoyos SE, Nieto ML, Rubio FC, Cormenzana AR. Kinetics of aerobic treatment of olive mill waste water (OMW) with Aspergillus terreus. Process Biochem 2002;37:1169-76.

[31] Pascoal C, Cassio F. Contribution of fungi and bacteria to leaf litter decomposition in polluted river. Appl Environ Microbiol 2004;70(9):5266-73.

[32] Gibbs PA, Seviour RJ, Schmid F. Growth of filamentous fungi in submerged culture: problems and possible solutions. Crit Rev Biotechnol 2000;20:17-48. 
[33] Maldonado MC, Strasser de Saad AM. Production of pectinase and polygalacturonase by Aspergillus niger in submerged and solid state systems. J Ind Microbiol Biotechnol 1998;20:34-8.

[34] Metz B, Kossen NWF, van Suijdam JC. The rheology of mould suspensions. Adv Biochem Eng 1979;11:103-56.

[35] Olsvik E, Tucker KG, Thomas CR, Kristiansen B. Correlation of Aspergillus niger broth rheological properties with biomass concentra- tion and shape of mycelial aggregates. Biotechnol Bioeng 1993;42:104652 .

[36] Fatile IA. Rheological characteristics of suspensions of Aspergillus niger: correlation and shape of the mycelial aggregate. Biotechnol Bioeng 1985;21:60-4. 